\title{
The Key Elements on Selection of Training Outsourcing
}

\author{
Lu Sun \\ Harbin University of Commerce, China \\ E-mail: sunl@harbcu.edu.cn \\ Yanxin Zhang \\ Harbin University of Commerce, China \\ E-mail: zhangyx043059@yahoo.com.cn \\ Xingang Wang \\ Zhejiang Wanli University, China \\ E-mail:wxg024@163.com
}

Roger Su

Auckland University of Technology, New Zealand

E-mail: Roger.su@aut.ac.nz

Received: June 7, 2012

doi:10.5296/jmr.v4i4.1977
Accepted: July 4, 2012 Published: October 1, 2012

URL: http://dx.doi.org/10.5296/jmr.v4i4.1977

\begin{abstract}
In this paper, we develop a new index system for the selection of training outsourcing. With the new system, we find key elements of the selection of training outsourcing through factor analysis are helpful to improve the accuracy of decisions of the contracting business, which make contracting businesses select the vendor companies to meet their requirements.
\end{abstract}

Keywords: Training outsourcing, Human resource management, Key element, Factor analysis 


\section{Introduction}

In $21^{\text {st }}$ century, the employee value has become significant to business asset contracture. Therefore, many firms pay a lot to hire a high value staff and organize course for existing staff training to improve their knowledge and skill. Staff training is the main form of human resource development and is also one of the ways to enhance the competitiveness of enterprises, however, simply relying on their own internal resources to train staff has been unable to meet the development needs of corporate human resources. Therefore, many firms prefer to use external training organizations for personnel training, which would reduce cost and improve management efficiency. Such, it is important for a business to concern how they can select or choose an appropriate training organization.

Outsourcing was proposed by Gray Hamel and C. K. Prahalad in 1990, which refers to that enterprises outsourced some important but non-core business functions to professional outsourcing suppliers in order to improve the quality of services and products, short the production cycle and reduce costs, enterprises focus on those business that can create more value to maximize the potential efficiency and enhance the core competitiveness of companies ( $\mathrm{Lu}, 2009$ ). Outsourcing mainly includes production outsourcing, marketing outsourcing, R \& D outsourcing and human resource management outsourcing and so on. Training outsourcing as an important form means that enterprise entrust some or all of the training business to the professional training outsourcing provider by the way of bidding and the contract, monitor the entire process of training activities and evaluate the training effect in order to achieve the targets ( $\mathrm{Xu}$ and Mei,2007). Training outsourcing generally relates to the training plan, the design of training courses, training time, the choice of methods as well as a lecturer, the assessment and feedback of training effectiveness and so on. Training outsourcing can be a more specialized division of labor, corporate outsourced training business to suppliers, which is very helpful to simply the complexity of management and to improve the core competitiveness of enterprises allowing companies to focus on business advantages and to reduce the cost (Lin, Zhang and Wang, 2008).

From previous literature, exception of risk and motivation of outsource, we do not find any studies on key elements of supplier selection of training outsourcing. In this paper, we will study what kinds of elements which may affect business to select a training outsourcing, which will provide a theoretical knowledge to firms when they looking for a training outsourcing provider

\section{Method of Factor Analyses}

Factor analysis originated in the early $20^{\text {th }}$ century and was proposed by K. Pearson and C. Spearman to define and measure intelligence by the statistical analysis (Lin and Qian, 2010). According to the internal dependencies of the correlation matrix, factor analysis integrated some variables with intricate relationship to few factors. Factor analysis is statistical method to determine the essence and classification of certain variables by use of different factors. In a word, variables are grouped on the basis of the correlation, so variables within the same group have higher correlation and less correlation within different groups. Each variable represents a basic structure, this basic structure is called factor (Hou, 2010). Therefore, factor 
analysis can be used to identify a few potential factors, which hidden in a large number of observed variables.

Generally, we can use variables for factor analysis, its mathematical model is expressed as follows:

We assume several variables, $X_{i}(i=1,2, \ldots \ldots, p) p$, the expression as follows: $X_{i}=a_{i 1} F_{I^{+}}$ $a_{i 2} F_{2}+\ldots+a_{i m} F_{m}+\varepsilon_{i} \quad(m \leq p)$

The second type of expression as follow:

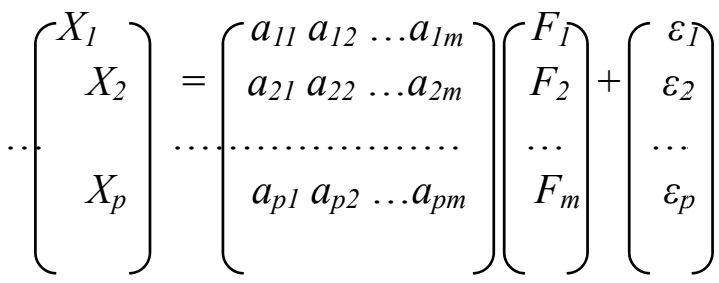

$$
\begin{aligned}
& X=A F+\varepsilon
\end{aligned}
$$

The common factor is unobservable variable such as $F_{1}, F_{2}, \ldots F_{m}$. Their coefficients $\left(a_{i j}\right)$ are called factor loading, $\varepsilon_{i}$ is special factor and can not be included by the former several common factors. And, $\operatorname{cov}(F, \varepsilon)=0, F, \varepsilon_{i}$ represents there is no correlation between variables.

Two core issues of factor analysis are how to construct the factor variable and to name explanation, there are four basic steps for factor analysis: (1)determine whether the original numbers of variables is appropriate or not; (2)construct factor of variables; (3)make factor variables have interpretability by using rotation; (4)calculate the score of factor variables (Sun, 2008).

\section{Literature Review}

Wang and Wang (2007) point out that the main factors about selecting providers included the reputation, financial condition, training experience, relevant documents, recruitment and training, shared values, the relevant data, time and the commitments. Ren and Cun (2008) use AHP on quantitative research on the selection of training contractor and find some factors such as cultural cohesion, motivating force and compatible degrees, staff, customers, contract management, brand, reputation, the recognition of industry, curriculum design, training effects are important for outsource provider selection. Tang, Sun and Gao (2008) establish an index system of selection evaluation of training outsourcing vendor including industry status, reputation, the richness degree of relevant training experience, the proportion of qualified trainers, the completeness of training materials, the level of cross-cultural management, corporate values match, the communication and coordination capacity of the training team, the price level of training and post-training follow-up service. Qing and Deng (2009) studied decision-making selection of training outsourcing provider by using AHP, and they believe 
main factors which will affect the decision of selecting training outsourcing are reputation, price, financial condition, professional quality and cultural degree of coupling.

Considering the enterprises actual needs of the outsourcing, suggestions from human resources experts and corporate executives, we in this paper develop a new evaluation system which includes ten indicators to judge whether an enterprise select a proper external resourcing training organization: the quality of training service, cultural degree of coupling, cultural cohesion and driving forces, training skills, the recognition of industry, training experience, the position in the industry, the relevant data, reputation and brand. The new evaluation system emphasize more on characteristics of service and the cooperation between the contracting companies, which can more accurately reflect the focus of the training outsourcers.

\section{The Analysis of Key Elements of Training Outsourcing}

According to the above ten selection indicators of training outsourcing, we build the Table 1 below following the Likert scale, the scale use five points to score, where one, two, three, four, five respectively represents this indicator is not very important, unimportant, important, more important and most important, the greater score means that outsourcers are more satisfied with the services of training outsourcing supplier. Expert Review Committee compose of human resource management experts, senior executives scored this criterion, and this scale is sent to twenty people to answer, the effective data after the recovery and analysis shown in Table 2:

Table 1. The Selection Criteria of Training Outsourcing and Likert Scale

\begin{tabular}{|c|c|c|c|c|c|c|}
\hline \multirow[t]{2}{*}{$\begin{array}{l}\text { Indicator } \\
\text { code }\end{array}$} & \multirow{2}{*}{$\begin{array}{l}\text { Supplier selection of criteria } \\
\text { of training } \\
\text { outsourcing(name of index) }\end{array}$} & $\begin{array}{l}\text { Not very } \\
\text { important }\end{array}$ & unimportant & important & $\begin{array}{c}\text { More } \\
\text { important }\end{array}$ & $\begin{array}{c}\text { most } \\
\text { important }\end{array}$ \\
\hline & & 1 & 2 & 3 & 4 & 5 \\
\hline$X 1$ & $\begin{array}{c}\text { The quality of training } \\
\text { services }\end{array}$ & & & & & \\
\hline$X 2$ & cultural degree of coupling & & & & & \\
\hline$X 3$ & $\begin{array}{l}\text { Cultural cohesion and } \\
\text { driving forces }\end{array}$ & & & & & \\
\hline$X 4$ & $\begin{array}{c}\text { Training skills and } \\
\text { experience }\end{array}$ & & & & & \\
\hline$X 5$ & Awareness of the industry & & & & & \\
\hline$X 6$ & Teacher resource & & & & & \\
\hline$X 7$ & The position in the industry & & & & & \\
\hline$X 8$ & The relevant data & & & & & \\
\hline$X 9$ & credit & & & & & \\
\hline$X 10$ & brand & & & & & \\
\hline
\end{tabular}




\section{Mll Macrothink}

Table 2. The Original Data

\begin{tabular}{|c|c|c|c|c|c|c|c|c|c|c|}
\hline $\begin{array}{c}\text { index } \\
\text { number }\end{array}$ & $X 1$ & $X 2$ & $X 3$ & $X 4$ & $X 5$ & $X 6$ & $X 7$ & $X 8$ & $X 9$ & $X 10$ \\
\hline 01 & 1 & 5 & 4 & 1 & 1 & 1 & 1 & 1 & 1 & 1 \\
\hline 02 & 2 & 5 & 5 & 2 & 2 & 2 & 1 & 2 & 1 & 1 \\
\hline 03 & 4 & 3 & 3 & 3 & 3 & 4 & 1 & 4 & 1 & 1 \\
\hline 04 & 4 & 3 & 4 & 4 & 4 & 4 & 2 & 4 & 2 & 2 \\
\hline 05 & 4 & 4 & 3 & 3 & 4 & 4 & 1 & 4 & 1 & 1 \\
\hline 06 & 4 & 3 & 3 & 3 & 4 & 3 & 2 & 3 & 1 & 2 \\
\hline 07 & 4 & 4 & 4 & 4 & 3 & 3 & 2 & 4 & 1 & 1 \\
\hline 08 & 1 & 5 & 3 & 1 & 1 & 1 & 1 & 1 & 1 & 1 \\
\hline 09 & 4 & 4 & 5 & 4 & 4 & 4 & 2 & 4 & 1 & 1 \\
\hline 10 & 5 & 4 & 3 & 5 & 4 & 5 & 3 & 5 & 3 & 3 \\
\hline 11 & 5 & 4 & 3 & 4 & 4 & 4 & 2 & 5 & 2 & 2 \\
\hline 12 & 5 & 4 & 5 & 4 & 4 & 5 & 3 & 5 & 2 & 2 \\
\hline 13 & 3 & 5 & 5 & 2 & 1 & 2 & 1 & 3 & 1 & 1 \\
\hline 14 & 5 & 3 & 4 & 3 & 3 & 3 & 2 & 5 & 2 & 2 \\
\hline 15 & 4 & 5 & 5 & 3 & 3 & 3 & 2 & 4 & 1 & 1 \\
\hline 16 & 4 & 4 & 4 & 4 & 5 & 3 & 1 & 4 & 1 & 1 \\
\hline 17 & 5 & 4 & 4 & 5 & 5 & 5 & 4 & 5 & 4 & 4 \\
\hline 18 & 5 & 4 & 4 & 2 & 4 & 3 & 1 & 5 & 1 & 1 \\
\hline 19 & 5 & 4 & 5 & 5 & 4 & 5 & 3 & 5 & 3 & 3 \\
\hline 20 & 5 & 4 & 4 & 5 & 5 & 5 & 2 & 5 & 1 & 2 \\
\hline
\end{tabular}

The target of factor analysis extracted few representative factors from the original indicator variables, so it is necessary to test the correlation between the indicator variables before the use of factor analysis, if the correlation is not strong, indicator variables is not suitable for factor analysis (Xu, and $\mathrm{Li}, 2009)$. The correlation between variables was verified by KMO and Bartlett's test. The value of the approximate chi-square is 226.757 (Table 3), the degree of freedom is 45 , the value of probability is 0.000 , the correlation matrix is not a unit matrix, so those variables can be analyzed by factor analysis. KMO is an index to use compared the value of observation indicators with the value of partial correlation coefficient, its value is closer to one, indicating that these variables are more appropriate to use factor analysis (Gong

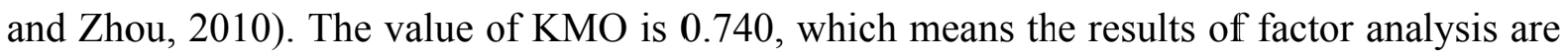
acceptable. 
Table 3. KMO and Bartlett's Test

Kaiser-Meyer-Olkin Measure of Sampling Adequacy

Bartlett's Test of Sphericity Approx Chi-Square

df

When the main factors were extracted to substitute the information in the original indicator variables, we obtain the cumulative variance and characteristic roots of each component (Table 4). There are three characteristic roots of factors are more than one and respectively called F1, F2 and F3. The explained variance of the fist principal component or the contribution rate is $62.82 \%$, the one of the second principal component or the contribution rate is $15.28 \%$, the one of the second principal component or the contribution rate is $11.13 \%$, moreover, the cumulative variance contribution rate of these three principal component is $89.22 \%$, which shown F1, F2 and F3 have covered $90 \%$ of content of the raw data with a strong representation.

Table 4. Total Variance Explained

\begin{tabular}{|c|c|c|c|c|c|c|c|c|c|}
\hline \multirow{2}{*}{$\begin{array}{l}\text { Compone } \\
\mathrm{nt}\end{array}$} & \multicolumn{3}{|c|}{ Initial Eigenvalues } & \multicolumn{3}{|c|}{$\begin{array}{c}\text { Extraction Sums of Squared } \\
\text { Loadings }\end{array}$} & \multicolumn{3}{|c|}{$\begin{array}{c}\text { Rotation Sums of Squared } \\
\text { Loadings }\end{array}$} \\
\hline & $\begin{array}{l}\text { Tota } \\
1\end{array}$ & $\begin{array}{l}\% \text { of } \\
\text { Varianc } \\
\mathrm{e}\end{array}$ & $\begin{array}{l}\text { Cumulative } \\
\%\end{array}$ & $\begin{array}{l}\text { Tota } \\
1\end{array}$ & $\begin{array}{l}\% \text { of } \\
\text { Varianc } \\
\mathrm{e}\end{array}$ & $\begin{array}{l}\text { Cumulative } \\
\%\end{array}$ & $\begin{array}{l}\text { Tota } \\
1\end{array}$ & $\begin{array}{l}\% \text { of } \\
\text { Varianc } \\
\mathrm{e}\end{array}$ & $\begin{array}{l}\text { Cumulative } \\
\%\end{array}$ \\
\hline $\mathrm{X} 1$ & $\begin{array}{r}6.28 \\
2\end{array}$ & 62.815 & 62.815 & $\begin{array}{r}6.28 \\
2\end{array}$ & 62.815 & 62.815 & $\begin{array}{r}4.42 \\
4\end{array}$ & 44.235 & 44.235 \\
\hline $\mathrm{X} 2$ & $\begin{array}{r}1.52 \\
8\end{array}$ & 15276 & 78.091 & $\begin{array}{r}1.52 \\
8\end{array}$ & 15.276 & 78.091 & $\begin{array}{r}3.19 \\
1\end{array}$ & 31.906 & 76.141 \\
\hline $\mathrm{X} 3$ & $\begin{array}{r}1.11 \\
3\end{array}$ & 11.132 & 89.223 & $\begin{array}{r}1.11 \\
3\end{array}$ & 11.132 & 89.223 & $\begin{array}{r}1.30 \\
8\end{array}$ & 13.082 & 89.223 \\
\hline $\mathrm{X} 4$ & .407 & 4.069 & 93.292 & & & & & & \\
\hline X5 & .293 & 2.931 & 96.222 & & & & & & \\
\hline X6 & .155 & 1.550 & 97.772 & & & & & & \\
\hline $\mathrm{X} 7$ & .117 & 1.166 & 98.938 & & & & & & \\
\hline $\mathrm{X} 8$ & .060 & .603 & 99.540 & & & & & & \\
\hline X9 & .042 & .420 & 99.961 & & & & & & \\
\hline $\mathrm{X} 10$ & .004 & .039 & 100.000 & & & & & & \\
\hline
\end{tabular}

Extraction Method: Principal Component Analysis

To calculate the factor loading matrix by principal component analysis, these data can specify 
the load of each factor on each variable, which is the extent (Table 5).

Table 5. Component Matrix

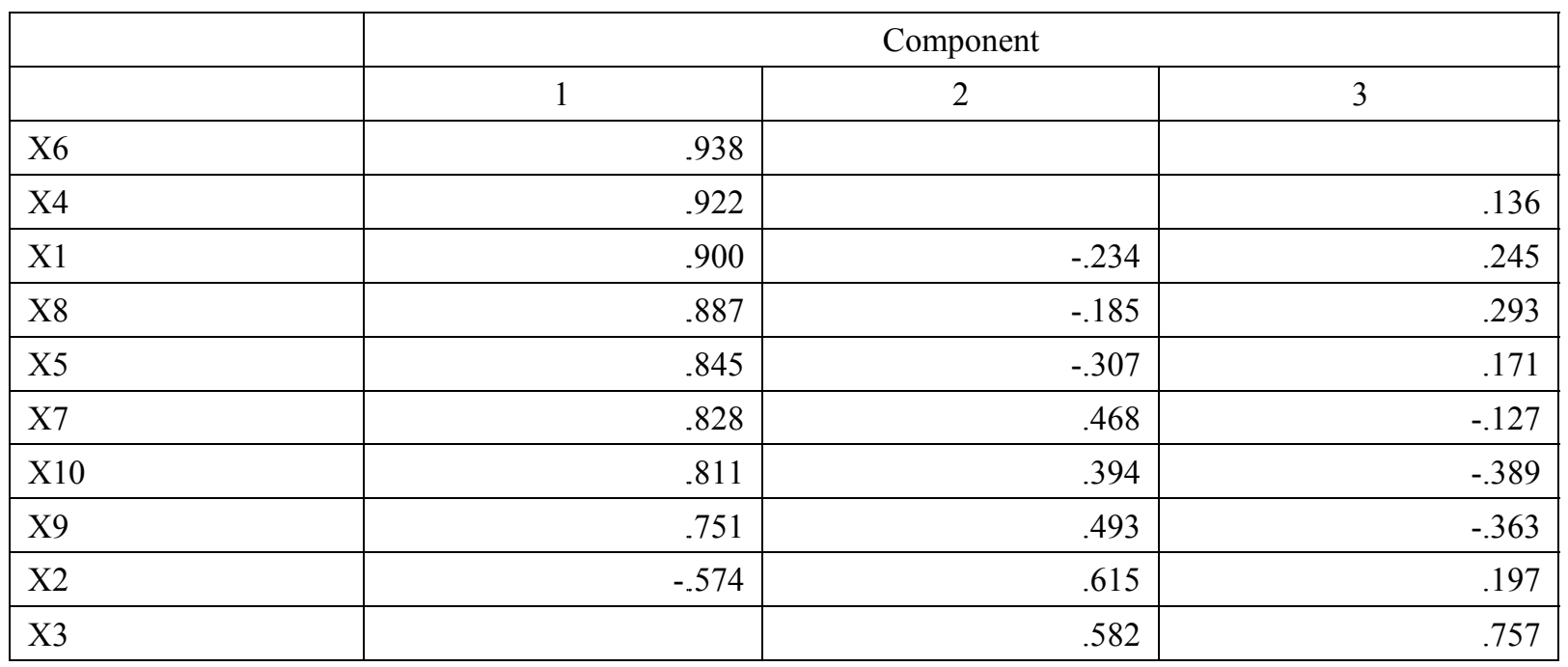

Extraction Method: Principal Component Analysis.

a. 3 components extracted.

However, the initial factor loading matrix was carried on orthogonal rotation in order to make coefficient differentiate from zero to one, the rotated factor loading matrix is shown in Table 6 below.

Table 6. Rotated Component Matrix

\begin{tabular}{|l|r|r|r|}
\hline \multicolumn{1}{|c|}{ The evaluation index of training outsourcing provider } & \multicolumn{3}{|c|}{ Component } \\
\cline { 2 - 4 } & \multicolumn{1}{|c|}{$\left.\begin{array}{r}\text { 1 } \\
\text { The quality of training service(X1) }\end{array}\right) .920$} & .282 & \\
Relevant data(X8) & .908 & .284 & \\
The recognition of industry(X5) & .876 & .236 & -.126 \\
Teacher source(X6) & .823 & .464 & \\
\hline Training skills and experience(X4) & .777 & .513 & \\
Cultural degree of coupling(X2) & -.636 & & .583 \\
credit(X9) & .223 & .943 & \\
brand(X10) & .302 & .928 & -.117 \\
The position of industry(X7) & .397 & .863 & .131 \\
Cultural cohesion and driving forces(X3) & & & .955 \\
\hline
\end{tabular}

Extraction Method: Principal Component Analysis.

Rotation Method: Varimax with Kaiser Normalization.

a. Rotation converged in 6 iterations 


\section{Macrothink}

With factor extraction and orthogonal rotation, we obtain three factors and the loading coefficient of ten indicators is above 0.5. The results of Rotated Component Matrix can make the meaning about factor variables clearer. F1 reflects the quality of training services, the relevant data, the recognition of industry, faculty strength and training skills and experience, so this factor variable is named as professional level. F2 presents reputation, brand and the position in the industry, so this factor variable is named as the overall image. F3 mainly stands for the cultural degree of coupling, cultural cohesion and driving forces, so the variable may be named corporate culture.

\section{Conclusions}

Specialization and the development of information technology promote more intense market competition; training outsourcing has become one of the inevitable choices for various types of enterprises. However, how to effectively select a proper training outsourcing provider has become significant. With our analysis and studies, we find that the contracting companies mainly take three indicators to select their appropriate training outsourcing providers, see Table 7.

Table 7. Selection Index System of Training Outsourcing

\begin{tabular}{|c|c|c|c|c|}
\hline $\begin{array}{c}\text { The first level } \\
\text { indicators }\end{array}$ & $\begin{array}{c}\% \text { of variance } \\
\text { explained }\end{array}$ & The second level indicators & Load factor & score mean \\
\hline \multirow{5}{*}{$\begin{array}{l}\text { Professional } \\
\text { standards }\end{array}$} & 62.815 & The quality of training service & 0.920 & 3.95 \\
\hline & 0.603 & Relevant data & 0.908 & 3.9 \\
\hline & 2.931 & The recognition of industry & 0.876 & 3.4 \\
\hline & 1.550 & Teacher resource & 0.823 & 2.15 \\
\hline & 4.069 & Training skills and experience & 0.777 & 3.35 \\
\hline \multirow{3}{*}{$\begin{array}{c}\text { The overall } \\
\text { image }\end{array}$} & 12.276 & credit & 0.583 & 4.05 \\
\hline & 0.420 & Brand & 0.943 & 1.55 \\
\hline & 0.039 & The position in the industry & 0.928 & 1.65 \\
\hline \multirow{2}{*}{$\begin{array}{l}\text { Corporate } \\
\text { culture }\end{array}$} & 1.166 & Cultural degree of coupling & 0.863 & 1.85 \\
\hline & 11.132 & $\begin{array}{l}\text { Cultural cohesion and driving } \\
\text { forces }\end{array}$ & 0.955 & 4 \\
\hline
\end{tabular}

In the first column, the first level indicators are classified and named by the rotated factor loading matrix in Table 6 . In the second column, $\%$ of variance explained is the percentage of the explanatory power for ten indicator variables. In the third column, the second level indicators were obtained by previous comments of selection criteria. The load factor (column 4) presents an index scale comparing the second level indicators to the fist level indicators, and derived by factor analysis. 


\section{Macrothink

The finding of key elements of the selection of training outsourcing through factor analysis are helpful to improve the accuracy of decisions of the contracting business, which make contracting businesses select the vendor companies to meet their requirements. As the same time, the choice of the key elements contribute to obtain appropriate indicators for enterprises in order to specify the relevant assessment criteria and refer to the different weights of the various indicators, which may be more operational selection and evaluation indicators of training outsourcing provider selection.

\section{References}

Hou, L. (2010). The research on performance evaluation of stock options for listed companies based on factor analysis. Reform \& Opening, 02, 55-57

Guan, H. and Zhou, J. (2010). Analysis of the competitiveness of regional financial outsourcing based on factor analysis. International Economics and Trade Research, 11, 39-43

Li, M. and Huang, H. (2009). An empirical research on indicators of HRM outsourcing vendor selection. Reformation \& Strategy, 07, 142-144

Lin, H., \& Qian, Y. (2010). The research on influencing factors of the core competitiveness in service outsourcing bases based on factor analysis. Pioneering with Science \& Technology Monthly, 09, 117-119

Lin, L., Zhang, P., \& Wang, Z. (2008). Outsourcing model selection of personnel training for SMEs. Economic and Technological Cooperation, 02, 50-51

Lu, H. (2009). Study on operating mode of training outsourcing of modern corporate. Commercial Modernization, 12, 289

Qing, F., \& Deng, Z. (2009). The study on decision method of training outsourcing suppliers based on AHP . Modern Business Trade Industry, 18, 19-20

Ren, L., \& Cun, X. (2008). The application analysis of AHP in contractors' training for their choice. Journal of Yunnan Agricultural University (Social Science), 06, 31-34

Sun, X. (2008). The study on competitiveness evaluation of service outsourcing. International Economics Trade Research, 07, 28-33

Tang, W., Sun, J., \& Gao, P. (2008). A fuzzy multi-attribute decision-making model for selection of training outsourcing supplier. Technology Economics, 09, 49-5i3

Wang, Q., \& Wang, Y. (2007). The construction and use of decision-making model for corporate training outsourcing . Training Corner, 10, 72-73

$\mathrm{Xu}, \mathrm{Y} .$, \& Li, W. (2009). Refinement of the key risk factors in software outsourcing projects. Modern Business, 08, 52-53

Xu, Y., \& Mei, J. (2007). The research and decision model of training outsourcing. Business Time, 23, 46-47 